\title{
Effect of Reoxygenation on the Electrical Stability of the Rat Heart In Vivo: A Chronobiological Study
}

\author{
P. ŠVORC ${ }^{1,2}$, A. MAROSSY ${ }^{1}$, P. ŠVORC Jr ${ }^{2}$, M. BUŽGA ${ }^{2}$ \\ ${ }^{1}$ Department of Physiology, Medical Faculty, Safarik University, Košice, Slovak Republic, \\ ${ }^{2}$ Department of Physiology, Medical Faculty, Ostrava University, Ostrava, Czech Republic
}

Received March 1, 2013

Accepted May 26, 2013

\section{Summary}

Reoxygenation following hypoxic episodes can increase the risk for the development of ventricular arrhythmias, which, in addition to circadian aspects of reoxygenation arrhythmias has not been studied extensively. The aim of the present study was to evaluate circadian changes in the electrical stability of the rat heart during reoxygenation following a hypoventilatory episode. The electrical stability of the heart, defined in the present study as the ventricular arrhythmia threshold (VAT), was measured at $3 \mathrm{~h}$ intervals at clock times 09:00, 12:00, 15:00, 18:00, 21:00, 24:00, 03:00, 06:00 and 09:00 during $20 \mathrm{~min}$ hypoventilation (20 breaths $/ \mathrm{min}$, tidal volume $=0.5 \mathrm{ml} / 100 \mathrm{~g}$ body weight [n=17]) and subsequent 20 min reoxygenation (50 breaths/min, tidal volume $=1 \mathrm{ml} / 100 \mathrm{~g}$ body weight $[\mathrm{n}=4]$ ) intervals. The experiments were performed using pentobarbital-anesthetized (40 mg/kg intraperitoneally) female Wistar rats that first underwent a four-week adaptation to a $12 \mathrm{~h}$ light:12 h dark regimen. Detailed analysis showed that circadian VATs changed to biphasic rhythms at $10 \mathrm{~min}$ of hypoventilation. The VAT circadian rhythms were observed immediately following the commencement of reoxygenation, with the highest values measured between 12:00 and 15:00, and the lowest values between 24:00 and 03:00. These results suggest that myocardial vulnerability is dependent on the light:dark cycle and characteristics of pulmonary ventilation.

\section{Key words}

Circadian rhythm - Electrical stability of the heart - Rat • Reoxygenation

\section{Corresponding author}

Pavol Švorc, Department of Physiology, Medical Faculty, Safarik University, Tr. SNP 1, 04001 Košice, Slovak Republic. E-mail: pavol.svorc@upjs.sk

\section{Introduction}

The onset and development of ventricular arrhythmias depend on many factors that are also associated with some disorders of pulmonary ventilation. However, not all previous studies have considered the effect of the resumption of oxygen delivery (i.e., reoxygenation) following hypoxic episodes on the onset or development of ventricular arrhythmias (Svorc and Podlubny 2002, Svorc et al. 2005). Reoxygenation following hypoxic episodes does not automatically normalize electrophysiological and mechanical myocardial properties, which can increase the risk for the onset of reoxygenation arrhythmias (Mubagwa et al. 1997, Shinmura et al. 1997, Guo et al. 2005).

The proarrhythmogenic effect of reoxygenation has been confirmed in previous studies using various agents. Tetrodoxin (a $\mathrm{Na}^{+}$channel blocker) and nicorandil (a $\mathrm{K}_{\mathrm{ATP}}$ channel opener that activates $\mathrm{K}_{\mathrm{ATP}}$ channels, causing $\mathrm{K}^{+}$efflux) decreased the occurrence of arrhythmias, probably by decreasing $\mathrm{Na}^{+}$current or by increasing the ATP-sensitive $\mathrm{K}^{+}$current, respectively (Hayashi et al. 1996, Hayashida et al. 1996). Thus, nicorandil antagonizes the cellular mechanisms that underly reoxygenation arrhythmias and prevents reoxygenation-induced arrhythmias ( $\mathrm{Xu}$ et al. 1993). Mitochondrial $\mathrm{K}_{\mathrm{ATP}}$ channel block is associated with protection from arrhythmogenesis during reoxygenation (Wakatsuki et al. 2009). The duration of reoxygenation arrhythmias was slightly reduced by increases in $\mathrm{Mg}^{2+}$ concentration and enhanced by decreases in $\mathrm{Mg}^{2+}$ concentration; however, this effect was not significantly different from controls. In contrast, low $\mathrm{K}^{+}$levels led to significant prolongation, while high $\mathrm{K}^{+}$levels led to 
significant abbreviation of reoxygenation arrhythmias (Borchard et al. 1997). $\mathrm{Ca}^{2+}$ influx, via reverse-mode $\mathrm{Na}^{+} / \mathrm{Ca}^{2+}$ exchange, has been demonstrated to play a key role in reoxygenation injury in guinea pig papillary muscles (Hayashi 2000, Mukai et al. 2000).

Hypoxia and reoxygenation expose the myocardium to extremes in redox stress, which can result in the initiation of a series of cellular pathways leading to tissue injury and death (Draper and Shah 1997, Kang et al. 2000). Hypoxia and reoxygenation are associated with additional damage to the myocardium through the oxidation of cellular components and activation of the inflammatory cascade (Cerniway et al. 2002). Dworschak et al. (2004) described the potentially harmful effects of accelerated oxygen radical production in association with diminished $\mathrm{Ca}^{2+}$ clearance or intracellular $\mathrm{Ca}^{2+}$ accumulation during ischemia/reperfusion. These effects may be fatal and result in the generation of reactive oxygen species and subsequent tissue damage (Danielsson et al. 2007). Attenuation of reactive oxygen species production during hypoxia and reoxygenation significantly decreased pulmonary vein arrhythmogenesis and induced various electrophysiological responses in the right and left atria, which may play a role in the pathophysiology of atrial fibrillation (Lin et al. 2012).

Adenosine A1-receptor stimulation facilitates ventricular fibrillation in hearts subjected to hypoxia and reoxygenation (Chi et al. 1994). Indirectly, the inhibition of inducible nitric oxide synthase increases peroxidative and apoptotic activity in the hypoxic heart, indicating that this isoform may have a protective effect against hypoxia/reoxygenation injuries and, furthermore, challenging the conventional wisdom that the production of inducible nitric oxide synthase is deleterious under these conditions (Milano et al. 2010, Rus et al. 2011).

There is supportive evidence regarding the harmful effect of reoxygenation on the myocardium; however, some studies have reported results to the contrary. Using an experimental, in vivo porcine model, Abdel-Rahman et al. (2009) demonstrated that hypoxic reoxygenation at the onset of reperfusion attenuated myocardial ischemia/reperfusion injury and helped to preserve cardiac performance after myocardial ischemia.

Many studies investigating the effect of ischemia/reperfusion or hypoxia/reoxygenation on the onset and development of ventricular arrhythmias primarily concentrate on temporally current mechanical and metabolic changes in myocardial cells, often without regard to circadian dependence. Whether the vulnerability of the ventricles to arrhythmia is primarily influenced by factors related to altered ventilation, or whether there are additional natural factors (e.g., environmental periodicities) that can influence the parameter being evaluated remains to be determined.

\section{Methods}

\section{Ethics approval}

The present study was performed in accordance with the Guide for the Care and Use of Laboratory Animals, published by the United States National Institutes of Health (NIH publication number 85-23, revised 1996). The study protocol was also approved by the Ethics Committee of the Medical Faculty of Safarik University (Kosice, Slovak Republic) (permission number 2/05).

\section{Adaptation and anesthesia of animals}

Circadian fluctuations in the electrical stability of the heart, measured in the present study according to ventricular arrhythmia threshold (VAT), were examined in female, pentobarbital-anesthetized Wistar rats ( $40 \mathrm{mg} / \mathrm{kg}$ intraperitoneally) that had been adapted to a daily light-dark (LD) cycle of $12 \mathrm{~h}$ light:12 h dark (dark period from 18:00 to 06:00) for four weeks. The animals were housed two per cage at a temperature of $24{ }^{\circ} \mathrm{C}$ and humidity of $40 \%$ to $60 \%$, with ad libitum access to food and water.

Anesthesia was maintained at a level at which painful stimuli and surgery did not evoke noticeable motor or cardiovascular responses. On completion of the experiments, the animals were euthanized by cardiac administration of an overdose of pentobarbital.

\section{Experimental protocol}

The animals were randomly divided into two groups. Group 1 (normoxic group) was ventilated using normal parameters of artificial ventilation ( 50 breaths $/ \mathrm{min}$, tidal volume $=1 \mathrm{ml} / 100 \mathrm{~g}$ body weight [n=17]) and group 2 (hypo-reoxy) underwent $20 \mathrm{~min}$ hypoventilation $(20$ breaths $/ \mathrm{min}$, tidal volume $=$ $0.5 \mathrm{ml} / 100 \mathrm{~g}$ body weight $[\mathrm{n}=4]$ ) followed by $20 \mathrm{~min}$ reoxygenation at parameters of artificial normal ventilation.

The electrical stability of the heart was defined by VAT, which was measured directly through the electrical stimulation of the right ventricle during open chest experiments. VAT measurements were performed 

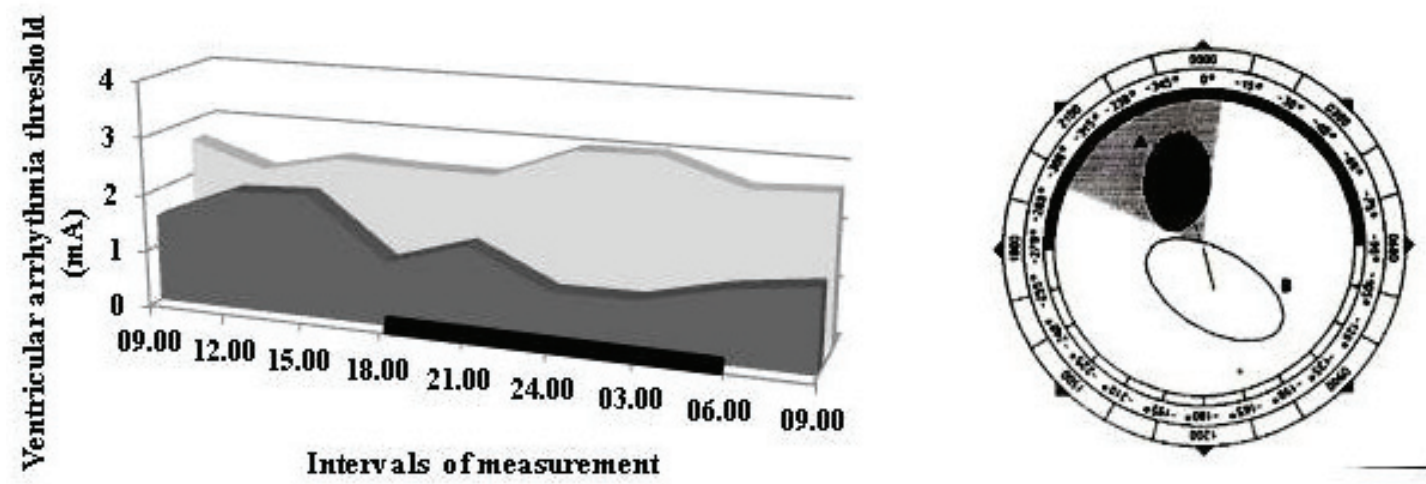

Fig. 1. Left: Circadian rhythms of the VAT during normoventilation (light area) and reoxygenation (black area). Right: Cosinor presentation of these rhythms during normoventilation (full ellipse) and reoxygenation (empty ellipse). The values represent means \pm SD. The black bar on the $x$-axis and the cosinor diagram indicates the dark period of the rat light-dark cycle.

at $3 \mathrm{~h}$ intervals at clock times of approximately 09:00, $12: 00,15: 00,18: 00,21: 00,24: 00,03: 00,06: 00$ and 09:00, while the rat was supine. The VAT measurements were performed at a temperature equivalent to the rectal temperature of the animal, which was measured before administration of the anesthetic agent. The body temperature of the animals was maintained using an infrared heat lamp.

\section{Measurement of VAT}

VAT was estimated as the minimal amount of electrical current (in $\mathrm{mA}$ ) required to elicit a ventricular arrhythmia. The stimulating electrodes $(1 \mathrm{~mm}$ in diameter; $5 \mathrm{~mm}$ interelectrode distance) were fixed at the base of the right ventricle while the animal was supine. Cardiac stimulation (using rectangular pulses with a frequency of $30 \mathrm{~Hz}$, impulse length of $10 \mathrm{~ms}$ and duration of stimulation of $400 \mathrm{~ms}$ ) was triggered by the initial pulse of the $\mathrm{R}$ wave. The current intensity was progressively increased in increments of $0.2 \mathrm{~mA}$ until ventricular arrhythmias were elicited. The parameters used for stimulation were chosen so that at least one impulse was applied during the vulnerable period, provided the duration of the stimulation covered a minimum of two to three heart cycles. The ventricular arrhythmias were of mixed type, with spontaneous mutual transitions among ventricular fibrillation, ventricular tachycardia and flutter, and were comparable between the two groups.

\section{Statistical analyses}

Results are expressed as mean $\pm \mathrm{SD}$. The basic circadian parameters were assessed using single and population mean cosinor tests. The data were obtained from experiments that were conducted over the seasons because circannual variation can also occur in the parameters that were examined.

\section{Results}

In the normoxic group, the acrophase of the significant VAT circadian rhythm was $-338^{\circ}$ (95\% CI $-288^{\circ}$ to $-7^{\circ}$ ) at $22: 53$ (95\% CI $19: 20$ to $\left.00: 28\right)$, with mesor $2.59 \pm 0.53 \mathrm{~mA}$ and amplitude $0.33 \pm 0.11 \mathrm{~mA}$ (Fig. 1).

In the hypo-reoxy group, more detailed analysis of changes in circadian VAT after $5 \mathrm{~min}, 10 \mathrm{~min}, 15 \mathrm{~min}$ and $20 \mathrm{~min}$ of hypoventilation showed that the acrophases from $10 \mathrm{~min}, 15 \mathrm{~min}$ and $20 \mathrm{~min}$ of hypoventilation were nonsignificantly shifted compared with $5 \mathrm{~min}$ of hypoventilation (Table 1). The characteristic biphasic course of the VAT circadian rhythms was apparent only after $10 \mathrm{~min}$ of hypoventilation (Fig. 2). An inverse course of VAT circadian rhythms were_observed immediately following the commencement of reoxygenation with the highest values measured between 12:00 and 15:00, and the lowest values between 24:00 and 03:00 compared to normoxic group. Mesor was decreased (1.41 mA), amplitude was increased $(0.57 \mathrm{~mA})$ and acrophase was $-165 \pm 20^{\circ}$

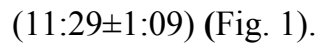

\section{Discussion}

The aim of the present study was to analyze circadian rhythms of VAT under conditions of reoxygenation following a period of hypoventilation. Hypoventilation and recovery of pulmonary ventilation produce different myocardial responses to electrical stimulation of the heart in individual animals. 
Table 1. Parameters of ventricular arrhythmia threshold circadian rhythms in single intervals of measurement in a rat model of hypoventilation/reoxygenation.

\begin{tabular}{|c|c|c|c|c|c|c|c|c|}
\hline & \multicolumn{4}{|c|}{ Initial hypoventilation } & \multicolumn{4}{|c|}{ Subsequent reoxygenation } \\
\hline & $5 \mathrm{~min}$ & $10 \mathrm{~min}$ & $15 \mathrm{~min}$ & $20 \mathrm{~min}$ & $5 \mathrm{~min}$ & $10 \mathrm{~min}$ & $15 \mathrm{~min}$ & $20 \mathrm{~min}$ \\
\hline Mesor & $1.32 \pm 0.1$ & $1.17 \pm 0.2$ & $0.15 \pm 0.2$ & $0.12 \pm 0.1$ & $1.41 \pm 0.1$ & $1.41 \pm 0.1$ & $1.29 \pm 0.1$ & $1.42 \pm 0.1$ \\
\hline Amplitude & $0.33 \pm 0.2$ & $0.33 \pm 0.2$ & $0.35 \pm 0.2$ & $0.20 \pm 0.2$ & $0.41 \pm 0.2$ & $0.48 \pm 0.1$ & $0.37 \pm 0.2$ & $0.53 \pm 0.1$ \\
\hline \multicolumn{9}{|l|}{ Acrophase } \\
\hline Degrees & $-356 \pm 25$ & $-11 \pm 37$ & $-36 \pm 30$ & $-30 \pm 58$ & $-166 \pm 24$ & $-165 \pm 17$ & $-172 \pm 29$ & $-156 \pm 10$ \\
\hline Hours & $23: 50 \pm 1.40$ & $00: 44 \pm 2.28$ & $02: 24 \pm 2.00$ & $02: 50 \pm 2.32$ & $11: 04 \pm 1.36$ & $11: 00 \pm 1.08$ & $11: 28 \pm 1.56$ & $10: 24 \pm 0.4$ \\
\hline
\end{tabular}

Data presented as mean $\pm \mathrm{SD}$

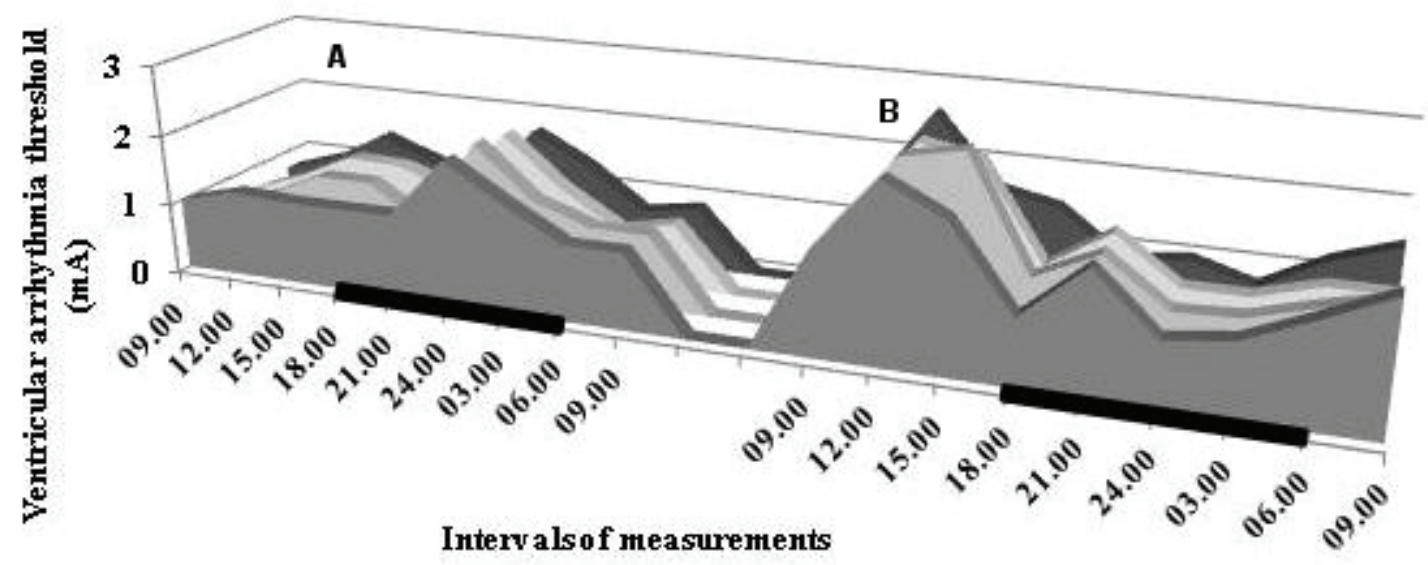

Fig. 2. Circadian rhythms of the VAT from the hypoventilation/reoxygenation model in order after $5 \mathrm{~min}, 10 \mathrm{~min}, 15 \mathrm{~min}$ and $20 \mathrm{~min}$ of the respective ventilation. A: Initial hypoventilation. B: Subsequent reoxygenation. The black bar on the $x$-axis indicates the dark period of the rat light-dark cycle.

Study limitations can be the absence of data regarding VAT parameters in nonanesthetized animals and the LD dependence of VAT parameters represented a limitation of the present study. These data, however, are also lacking in the literature. In addition, there was a relatively large dispersion of the values measured in the present study. VAT values revealed intra- and interindividual variability, which is an issue inherent to in vivo studies. The discrepancies can be explained by spontaneous, unpredictable alterations in the electrophysiological properties of the heart induced by anesthesia, or hormonal and homeostatic reflexes in the animals.

As mentioned above, changes in myocardial vulnerability depend primarily on changes in ion concentrations or on the activity of ion-exchange systems; LD differences in the electrical stability of the heart may also directly reflect LD differences in these systems. In hypoxia/reoxygenation or ischemia/reperfusion models, more studies have described myocardial $\mathrm{Ca}^{2+}$ accumulation. $\mathrm{Ca}^{2+}$ overload in myocytes is one of the many causes of reperfusion injury (Mubagwa et al. 1997, Shinmura et al. 1997, Sharikabad et al. 2000). It was hypothetized that the delay afterdepolarization, which produces the substrate for the genesis of serious ventricular dysrhythmias (i.e., $\mathrm{Ca}^{2+}$-mediated, non re-entry arrhythmias), is the result of such $\mathrm{Ca}^{2+}$ overload (Whalley et al. 1995). Sharikabad et al. (2000) described unchanged intracellular concentrations of $\mathrm{Ca}^{2+}$ ions during hypoxia; however, intracellular concentrations of $\mathrm{Ca}^{2+}$ ions were three to four times higher during reoxygenation in isolated rat hearts. During reoxygenation of hypoxic rat cardiomyocytes, a correlation exists between extracellular $\mathrm{Ca}^{2+}$ concentration and the levels of reactive oxygen species (the second factor involved in ischemia/reperfusion-induced cardiomyocyte damage), whereas the correlation between intracellular $\mathrm{Ca}^{2+}$ 
concentration and the level of reactive oxygen species is less consistent. These results indicate that the levels of reactive oxygen species during oxidative stress are at least partly dependent on extracellular $\mathrm{Ca}^{2+}$ concentration; however, reactive oxygen species (e.g., $\mathrm{H}_{2} \mathrm{O}_{2}$ ) can increase or decrease cardiomyocyte $\mathrm{Ca}^{2+}$ accumulation during reoxygenation in a concentrationdependent manner (Sharikabad et al. 2004). Decreases in intracellular $\mathrm{pH}$ may also play a role in the mechanism of myocardial damage during reoxygenation. This decrease is mediated, at least in part, by anion exchange stimulation $\left(\mathrm{Cl}^{-} / \mathrm{HCO}_{3}{ }^{-}\right.$exchange) through protein kinase $\mathrm{C}$ activation. This exchange occurs in reoxygenationinduced $\mathrm{Ca}^{2+}$ overload as well as contractile dysfunction (Kawasaki et al. 2001). Decreases in the electrical stability of the heart can also be the result of cellular $\mathrm{K}^{+}$ loss during hypoxia (Shivkumar et al. 1997). Hypoxia significantly decreases the duration of action potentials, probably through the activation of $\mathrm{K}_{\mathrm{ATP}}$ channels and increased $\mathrm{K}^{+}$ion efflux (Perchenet and Kreher 1995). The inhibition of outward $\mathrm{K}^{+}$currents demonstrated a cardioprotective effect during reperfusion (Liu et al. 1993, Tosaki et al. 1996). Increases in the intracellular concentration of $\mathrm{Na}^{+}$ions in myocardial cells and $\mathrm{Ca}^{2+}$ overload can contribute to the onset of reoxygenation arrhythmias (Kamiyama et al. 1996, Shinmura et al. 1997).

Hypoxia likely increases vulnerability to reoxygenation damage by reducing antioxidant reserve capacity. Reoxygenation, either by ventilator or cardiopulmonary bypass, produces oxidative damage with resultant functional depression (Ihnken et al. 1995).

Two important and unanswered questions remain: Are the mechanisms responsible for the altered circadian rhythm of myocardial vulnerability mobilized primarily by hypoventilation-induced systemic asphyxia and reoxygenation, with an additive effect of the LD cycle, or are they mobilized by oscillating factors in circadian dependence, with an additive effect of hypoventilation/reoxygenation? The observed changes in the electrical stability of the heart at the change of pulmonary ventilation reflect circadian fluctuations and significant dependence on the LD cycle also in pentobarbital-anesthetized rats. It affirms that LD differences in myocardial vulnerability are not only transient events or events that are dependent on experimental methods. Rather, it is a systemic response regulated by different neurohumoral pathways in the dark (active) and in the light (nonactive) part of the day. From a clinical perspective, synchronization to local time may also be an important factor in the evaluation of cardiovascular risk in patients with various respiratory disorders.

\section{Conflict of Interest}

There is no conflict of interest.

\section{References}

ABDEL-RAHMAN U, RISTESKI P, TIZI K, KERSCHER S, BEJATI S, ZWICKER K, SCHOLZ MU, BRANDT U, MORITZ A: Hypoxic reoxygenation during initial reperfusion attenuates cardiac dysfunction and limits ischemia-reperfusion injury after cardioplegic arrest in a porcine model. J Thorac Cardiovasc Sur 137: 978982, 2009.

BORCHARD U, BERGER F, HAFNER D, HERMSEN D, PICKER O: Electrophysiologic effects of $\mathrm{K}^{+}$and $\mathrm{Mg}^{2+}$ in the hypoxia model. Herz 22 (Suppl 1): 28-35, 1997.

CERNIWAY RJ, MORRISON RR, BYFORD AM, LANKFORD AR, HEADRICK JP, VAN WYLEN DGL, MATHERNE GP: $A_{1}$ adenosine receptor overexpression decreases stunning from anoxia-reoxygenation: role of the mitochondrial $\mathrm{K}_{\mathrm{ATP}}$ channel. Basic Res Cardiol 97: 232-238, 2002.

CHI L, FRIEDRICHS GS, OH JY, GREEN AL, LUCCHESI BR: Effect of Ado A1- and A2-receptor activation on ventricular fibrillation during hypoxia-reoxygenation. Am J Physiol 267: H1447-H1454, 1994.

DANIELSSON BR, DANIELSSON C, NILSSON MF: Embryonic cardiac arrhythmia and generation of reactive oxygen species: common teratogenic mechanism for IKr blocking drugs. Reprod Toxicol 24: 42-56, 2007.

DRAPER NJ, SHAH AM: Beneficial effects of a nitric oxide donor on recover of contractile function following brief anoxia in isolated rat heart. J Mol Cell Cardiol 29: 1195-1205, 1997.

DWORSCHAK M, BREUKELMANN D, HANNON JD: The impact of isoflurane during simulated ischemia/reoxygenation on intracellular calcium, contractile function, and arrhythmia in ventricular myocytes. Anesth Analg 99: 1302-1307, 2004. 
GUO H, TAKAHASHI S, CHO S, HARA T, TOMIYASU S, SUMIKAWA K: The effects of dexmedetomidine on left ventricular function during hypoxia and reoxygenation in isolated rat hearts. Anesth Analg 100: 629-635, 2005.

HAYASHI H: Pathogenesis and the role of $\mathrm{Ca}^{2+}$ overload during myocardial ischemia/reperfusion. Nagoya J Med Sci 63: 91-98, 2000.

HAYASHI H, TERADA H, KATOH H, MCDONALD TF: Prevention of reoxygenation-induced arrhythmias in guinea pig papillary muscles. J Cardiovasc Pharmacol 27: 816-823, 1996.

HAYASHIDA Y, HIRAKAWA H, NAKAMURA T, MAEDA M: Chemoreceptors in autonomic responses to hypoxia in conscious rats. In: Frontiers in Arterial Chemoreception. ZAPATA P, EYZAGUIRRE C, TORRANCE RW (eds), Plenum Press, New York, 1996, pp 439-442.

IHNKEN K, MORITA K, BUCKBERG GD, MATHEIS G, SHERMAN MP, ALLEN BS, YOUNG HH: Studies of hypoxemic/reoxygenation injury: without aortic clamping. II. Evidence for reoxygenation damage. Thorac Cardiovasc Surg 110: 1171-1181, 1995.

KAMIYAMA T, TANONAKA K, HAYASHI J, TAKEO S: Effects of aprindine on ischemia/reperfusion-induced cardiac contractile dysfunction of perfused rat heart. Jpn J Pharmacol 70: 227-234, 1996.

KANG PM, HAUNSTETTER A, AOKI H, USHEVA A, IZUMO S: Morphological and molecular characterization of adult cardiomyocyte apoptosis during hypoxia and reoxygenation. Circ Res 87: 118-125, 2000.

KAWASAKI H, OTANI H, MISHIMA K, IMAMURA H, INAGAKI C: Involvement of anion exchange in the hypoxia/reoxygenation-induced changes in $\mathrm{pH}_{\mathrm{i}}$ and $\left[\mathrm{Ca}^{2+}\right]_{\mathrm{i}}$ in cardiac myocyte. Eur J Pharmacol 411: 35-43, 2001.

LIN YK, LAI MS, CHEN YC, CHENG CC, HUANG JH, CHEN SA, CHEN YJ, LIN CI: Hypoxia and reoxygenation modulate the arrhythmogenic activity of the pulmonary vein and atrium. Clin Sci (Lond) 122: 121-132, 2012.

LIU J, TANONAKA K, SANBE A, YAMAMOTO K, TAKEO S: Beneficial effects of quinidine on post-ischemic contractile failure of isolated rat hearts. J Mol Cell Cardiol 25: 1249-1263, 1993.

MILANO G, CORNO AF, SAMAJA M, MOREL S, VASSALLI G, VON SEGESSER LK: Daily reoxygenation decreases myocardial injury and improves post-ischaemic recovery after chronic hypoxia. Eur J Cardiothor Surg 37: 942-949, 2010.

MUBAGWA K, KAPLAN P, FLAMENG W: The effects of ryanodine on calcium uptake by the sarcoplasmic reticulum of ischemic and reperfused rat myocardium. Fund Clin Pharmacol 11: 315-321, 1997.

MUKAI M, TERADA H, SUGIYAMA S, SATOH H, HAYASHI H: Effects of a selective inhibitor of $\mathrm{Na}^{+} / \mathrm{Ca}^{2+}$ exchange, KB-R7943, on reoxygenation-induced injuries in guinea pig papillary muscles. $J$ Cardiovasc Pharmacol 3: 121-128, 2000.

PERCHENET L, KREHER P: Mechanical and electrophysiological effects of preconditioning in isolated ischemic/reperfused rat heart. $J$ Cardiovasc Pharmacol 26: 831-840, 1995.

RUS A, DEL MORAL ML, MOLINA F, PEINADO MA: Does inducible NOS have a protective role against hypoxia/reoxygenation injury in rat heart? Cardiovasc Pathol 20: e17-e25, 2011.

SHARIKABAD MN, HAGELIN EM, HALBERG IA, LYBERG T, BRØRS O: Effect of calcium on reactive oxygen species in isolated rat cardiomyocytes during hypoxia and reoxygenation. J Mol Cell Cardiol 32: 441-452, 2000.

SHARIKABAD MN, ØSTBYE KM, BRØRS O: Effect of hydrogen peroxide on reoxygenation-induced $\mathrm{Ca}^{2+}$ accumulation in rat cardiomyocytes. Free Radical Biol Med 37: 531-538, 2004.

SHINMURA K, TANI M, SUGANUMA Y, HASEGAWA H, EBIHARA Y, NAKAMURA Y, ASAKURA Y: Effects of alpha(1)-adrenoreceptor subtype blockade on ischemia-reperfusion injury. Jpn Circ J 61: 927-935, 1997.

SHIVKUMAR K, DEUTSCH NA, LAMP ST, KHUU K, GOLDHABER JJ, WEISS JN: Mechanism of hypoxic K loss in rabbit ventricle. J Clin Invest 100: 1782-1788, 1997.

SVORC P, PODLUBNY I: Modulatory influence of ventilator disorders on electrical stability of the rat heart. Biomed Pharmacother 56 (Suppl 2): 327-332, 2002.

SVORC P, BENACKA R, PETRASOVA D, BRACOKOVA I, KUJANIK S: Effect of systemic hypoxia and reoxygenation on electrical stability of the rat myocardium: chronophysiological study. Physiol Res 54: 319$325,2005$. 
TOSAKI A, ENGELMAN DT, ENGELMAN RM, DAS DK: The evolution of diabetic response to ischemia/reperfusion and preconditioning in isolated working rat hearts. Cardiovasc Res 31: 526-536, 1996.

WAKATSUKI D, SHIMOJIMA H, HIGASHI Y, SUZUKI H, TAKEYAMA Y: Inhibition of mitochondrial KATP channel can improve conduction delay induced by angiotensin II during early reoxygenation. $J$ Mol Cell Cardiol 46: 443, 2009.

WHALLEY DW, WENDT DJ, GRANT AO: Electrophysiologic effects of acute ischemia and reperfusion and their role in the genesis of cardiac arrhythmias. In: Cardiac Arrhythmias: Mechanisms, Diagnosis and Management. PODRID PJ, KOWEY PR (eds), Williams and Wilkins, Philadelphia, 1995, pp 109-130.

XU YG, YANG XY, YAO RM, YANG YZ, CHEN HZ: Protective effects of nicorandil on action-potentials in anoxia and reoxygenated ventricular myocardium of guinea-pig. Acta Pharmacol Sinica 14: 186-189, 1993. 